\title{
Transformation of Russian Higher Education in the Information Society Conditions
}

\author{
Elena Sokurenko \\ Federal State Educational Budgetary Institution of Higher Education \\ Financial University under the Government of Russian Federation \\ (Financial University) \\ Moscow, Russia 125993 \\ E-mail: egsokurenko@yandex.ru
}

\begin{abstract}
The article examines the changes that are occurring in the modern system of Russian higher education, are associated with the transition of Russia from an Industrial society to an Information society (Knowledge society), in the process of which the majority of social institutions are transformed. The paper notes that the reform of the system of higher education in Russia is determined by an objective necessity caused by the requirements for ensuring an evolutionary transition to a new type of society and the formation of a competitive and versatile personality of the information society era.
\end{abstract}

Keywords-education system; higher education; reformation of higher education; competency forming; computer revolution; information society; transformation of social institutions

\section{INTRODUCTION}

The ongoing reform of the educational system in Russia is in many ways dictated by the transition from the Industrial to the Information society. Because of that, the educational system was assigned a new function - personnel training for the emerging Information society. The system of higher education always was conservative and stable. Because of that, any systematic modernization, caused by objective process of change in economics, politics and other spheres of Russian state, for the sake of continuity of traditions should happen evolutionary.

The transition from Industrial to Information society is, first of all, due to the transformation of production sphere. Unlike the Industrial society which is presupposing the occupation of large amount of citizens in routine production, Information society presupposes maximized automation of the process of production of consumer goods and minimization of the human's participation in labor process.

\section{FORMATION AND DEVELOPMENT OF RUSSIAN HIGHER EDUCATION IN THE TRANSITION TO AN INFORMATION SOCIETY}

At the beginning of the transition from Industrial to Information society, A. Toffler wrote "A new civilization is emerging in our lives, and blind men are trying to suppress it. This new civilization brings with it new family styles, changed ways of working, loving and living, a new economy, new political conflict; and beyond all this is altered consciousness as well. Pieces of this new civilization exist today" [1, P. 26].

The making of a new civilization does not happen overnight. The processes of automation of factories and plants had began from the moment of transition from Traditional to Industrial society, and occurred throughout the entire Industrialization period. But during the last decades of XX century they were sped up and conditioned by the transition of one social formation to another. Technological revolution, that has gained its momentum, caused the emergence of fundamentally new computer technologies and the creation of easily reprogrammed software. As such, if in Industrial society the creation of several similar parts with slight technological differences required several expensive machines, which significantly complicated and raised the price of production, then XXI century machine software allowed the creation of several variants of a product in one automated workplace. Таким образом, производство стало более мобильным и быстроменяющимся. As such, the production became more mobile and fast-changing. All of this is due to the world's system of higher education as a whole and Russian system of higher education in particular, which during the period of developed Industrial society had prepared the specialists that were able to begin the transition of the civilization to the new stage of being - the Information society.

But since this transition is still happening, at this moment Russian system of education is undertaking severe changes. The developments that allow to teach several expert innovators are very important, but the society has new needs. It needs University graduates of another formation. Modern Knowledge society doesn't need a few expert innovators of the highest qualifications, but an entire class of highly professional employees that possess knowledge, skills and abilities that exceed those of their predecessor graduates, that are able to compete at the international labor market.

Russia's interactions with foreign countries, its entry into WTO, its membership in the Bologna Process - all of this 
was reflected on the federal level. New Federal State Educational Standards (FSES) that were introduced after entering the Bologna Process, had brought many changes considering the structure and the contents of the educational process. Now the Higher education includes secondary vocational education, baccalaureate, specialty and magistracy, post-graduate professional education. All this had made the recognition of Russian diplomas abroad much easier, and increased competitive ability of graduates. Furthermore, the students had gained the opportunity to undergo not one, but several types of training during their education (bachelor's degree in one profile, master's degree in another), which is especially topical in the constantly changing conditions of Information society, answers the needs of students and the most in demand on labor market

The principles of education change as well. The emergence of Global Internet Network, the priorities of knowledge of a specialist on labor market had changed. The ones that are most in demand are not individuals that had memorized the most information in their profession but the ones who can operate it. That is why, while studying a new subject, according to new FSES, a student needs not only to demonstrate the knowledge of theoretical material on the studied discipline, but also corresponding skills. Entire groups of competence are represented in the current FSES. In other words, according to laws, University graduates must not only possess professional and general professional competences, but also have high general culture level that is necessary for a human of the new civilization.

At the beginning of the introduction of FSES, these standards were not universal. Every University teacher developed his own competences. As such, subject teaching depended on which teacher on the list of the department of University had went out to students. Change of a teacher, due to production (or other) necessity caused the same group of students learning the same subject to earn different competences, which every particular teacher thought to be appropriate for them. This brought confusion and disoriented the students.

The next stage of the introduction was the unification of competences on University level. But teachers of different disciplines could chose same competences for their subjects, leaving a number of more complex but just as important ones outside the curriculum. And getting the education in different Universities in the same field had leaded to earning different set of competences, which did not allow employer to find the necessary labor personnel. As such emerged the need to introduce general competences for all the groups of students studying identical disciplines.

These competences were developed and set as Orders of Russian Ministry of Education and Science. Nowadays, in every University competences with the same number have general structure and general contents of requirements for students studying for the same area of study.

Mastering the competences in the condition of quickly changing realities of modern society is sometimes even more important than learning a number of knowledge on a subject, since knowledge of some sciences (for example, areas of computer science that study computer programs) are quickly getting obsolete, while transferred competencies allow to learn new information and remain a specialist in the chosen labor area. Besides, as noted above, with the general availability of Internet, exact data search or other theoretical information happens much faster than it was in Industrial society. Because of that, communication skills and the ability to look for and work with information had acquired great value.

The changes occurring in society and its new needs influenced the education system. The developments of engeneering, technologies and software products had introduced Universities to a new form of education. Now, Universities "are allowed to use e-learning and remote education technologies. When teaching people with disabilities e-learning and remote education technologies should provide an ability to receive and transmit information in forms available to them" [2].

The use of e-learning and remote education technologies create comfortable conditions of obtaining higher education not only for people with disabilities, but also for citizens that live far away from University or don't have an ability to study within the institution for family or other life reasons. E-learning and remote education technologies allow to solve another important problem arising before an individual combining studies and work, raising one's qualification and actualizing knowledge. At the level of society in general the tendency of acquiring education leads to increase in competition and the appearance of motivation to continue the education of other individuals, as such raising general education level. Herewith, introduction of these forms of education is economically profitable for Universities. Since it removes several budget expenditures of an educational institution. Firstly, usage and amortization of rooms, machinery, payments for service staff (room cleaning, wardrobe usage etc.). Secondly, remote lectures and other materials, once written on electronic medium, are uploaded to Internet on an address that's accessible to students. While seminars, consultations and lectures in an interactive form can occur via Internet in real time.

Herewith, for reasonable price that was set by an University, almost any number of students are able to receive education using e-learning and remote education technologies. This is important from the point of view of social fairness and realities of economical crisis of Russian state.

\section{SPECIFICITY OF HIGHER EDUCATION IN THE INFORMATION SOCIETY}

Information society, unlike Industrial society, possesses a high speed of social dynamics. Technological (computer) revolution, by changing the tools of production, is quickly changing the labor market. New professional demands of labor market to those entering Universities get outdated by the time they finish their education. Transitional period from Industrial to Information society is marked by huge social dynamic and high speed of social changes. Scientific achievements of the period of technological revolution are 
happening avalanche-like. The expenditure for invention and commissioning of new technologies of production had drastically lessened thanks to progressive development of information and software technologies, and introduction of technological changes into production became easier. Creation of software for new machinery or invention of other categorically new multifunction device requires less time, labor and economic expenditures, because part of the process is modeled and modified on computer technology level. Constant change of employers' demands leads to the need of educating students that possess the ability of selfeducation. It was always an important element of a person's education. V.L. Nechaev writes: self-education, it seems, will always be an independent link in the education system, complementing stationary education, providing individualization of a person's cultural development" [3, P. 97]. But it acquires special significance in Information society, when static knowledge, due to its high rate of obsolescence, with time turns into equivalent of its absence. As such, appears the necessity of constant education of individuals. Out-of-school training becomes one of the main forms of advanced training.

Self-education is an independent work of an individual that requires serious motivation and self-organization. As such, A.M. Matyushkin thinks: "...opportunities of selfdevelopment, that act as the readiness for self-education, appear upon reaching a high enough level of theoretical development, and in the presence of motivation. A common indicator of an ability to self-develop and self-educate is posing a question and a problem that determine the need for search, independent discovery or acquisition of new knowledge in the form of self-education system" [4, P. 39]. The training of a person of Information era forces the entire training and educational system from its very first stages (preschool, school, vocational, undergraduate and postgraduate education) to reveal the competencies needed for self-education in an individual. Moreover, the specifics of livelihood of a person in Information society demands constant self-education from him, since even higher education acquired in University, in this century of computer revolution can't provide the graduate with knowledge in his chosen area once and for his entire life. New technologies, inventions and outside conditions force individuals to increase their competitiveness for their entire lives. Because of that, "self education as a special kind of cognitive activity presumes: positive motivational activity, direction; significant manifestation of willpower, purposefulness and self-organization; high level of intellectual development; formation of a certain system of cognitive skills; high independence; ability to see and ask questions, problems; presence of adequate level of selfesteem" [5]. It is these qualities that a person in Information society must possess.

Yet another problem of education is information noise. From one perspective, the colossal mass of generally available knowledge that appeared in the Internet and facilitated search using computer search software, should make it easier to find and process information. From another perspective, the sheer amount of daily replenishing data exceeds the person's physiological ability to accept, comprehend, reflect and use this data. This problem is called "information explosion". Information processing specialist claim that by 1800 the collective sum of human knowledge had doubled every 50 years, by 1950 it doubled every 10 years, and by 1970 - every 5 years. The speed of knowledge doubling during the transition to new society is raising faster and faster, and strengthens with the "growing up" of the information society. But physiological abilities of a human as a species remain the same. The key changes are tied to the emergence of a technological method of information gathering, that was transformed into correct setting of tasks for computer search engines. Computer revolution had significantly changed the social structure of society, reflected on the market of goods and services. But these changes had gained special significance on the labor market.

So, J. Nesbitt in his work "Megatrends: Ten New Directions Transforming Our Lives" that came out in 1982, writes: "The real increase took place in information jobs. In 1950 , only 17 percents of us worked in information jobs. Now 60 percent of employed deal in information - as programmers, teachers, clerks, secretaries, accountants, brokers, managers, insurance workers, officials, lawyers, bankers, technical specialists. Besides, many workers do information jobs in companies that deal in production. Most Americans spend their time creating, saving or distributing information [6, P.14].

Work with information, search for it, its processing and usage are becoming the basis of interaction on labor market. Topicality of these processes is due to the consequences of the increasing flow of information. Information explosion is accompanied by "information noise" - consisting of "garbage" of data not needed by an individual, avalanchelike streams of which make the search of really important sources and data significantly harder.

\section{CONCLUSION}

As such, the reforming of the educational system in Russia is caused by an objective necessity and, despite the conservatism of the system, modernization must be evolutionary.

Due to the transition from Industrial to Information society transforms many social institutes, it often happens at revolutionary pace, but not overnight, and these changes are connected to technological, and especially computer, revolution.

For further transformations in society and leveling of undesirable consequences of transition from Industrial to Information society significant changes in Russian education system are necessary.

Such reforms in Russia began with the introduction of the new federal state educational standards, that divided higher education in three stages: baccalaureate, speciality, magistracy and postgraduate education. In federal state educational standard new universal competencies for all 
Universities are introduced: general culture; general professional and professional competencies.

The development of machinery, technology and software products had leaded to the creation of a new form of education - e-learning and remote education technologies, which made knowledge more available for all social groups in society, while remaining profitable for Universities.

New technologies, inventions and outside conditions urge individuals to be engaged in improving their competitiveness and self-education. Work with information, search for it, its processing and usage become the basis of interaction on labor market,

Consequently, all changes that occurred in the system of native higher education, are objectively necessary and are directed on creating the conditions for Russia to enter the new stage of development of technogenic civilization - the Information society.

\section{REFERENCES}

[1] Toffler A. The third Wave. N. - Y: Bantam Books. 1980.

[2] Order of Ministry of Education and Science of Russia from 03.12.2015 N 1408 "On approval of federal state educational standard of higher education in the field of 47.04.01 Philosophy (magistracy level)" (Registered in Ministry of Justice of Russia 31.12.2015 N 40496).

[3] Nechaev V.L. Sociology of education. M.: MSU Publishing House 1992.

[4] Matyushkin A.M. Psychological basics of readiness of a person to self-educate // Materials from 1st All-Union conference "Problems of uninterrupted education in modern conditions of social progress and STR. M., 1981. p. 37 - 41.

[5] Abakumova E.B. Theory of the problem of self-education in philosophical, psycho-philosophical and sociological literature // Actual goals of pedagogy: Materials from II International Scientific Conference. Chita, 2012.

[6] Naisbitt G. Megatrends: Ten New Directions transforming our Lives. N. - Y: Grand Central Publishing. 1982. 